\title{
Earthquakes Precursors
}

\author{
Dumitru Stanica and Dragos Armand Stanica \\ Institute of Geodynamics of the Romanian Academy \\ Romania
}

\section{Introduction}

Strong earthquake of magnitude 7 or more (on the Richter scale) strikes about once a year somewhere in the world and, several times triggers a cascade of follow-on events, such as tsunamis, floods, landslides, nuclear power plant crisis and public health catastrophes in the affected regions. Thus, during the 2004 Sumatra-Andaman earthquake and Indian Ocean tsunami nearly 230,000 people were killed and more than one million people were left homeless in 13 countries surrounding the Indian Ocean. The May 12th, 2008 earthquake in Western Sichuan, China and January 8th, 2010 earthquake in Haiti caused a death toll well over 75,000 and 320,000 people, respectively. The latest M9 Tohoku earthquake of March 11th 2011 in Japan was the biggest recorded earthquake ever to hit Japan. The earthquake triggered extremely destructive tsunami waves of up to 10 meters that struck Japan minutes after the quakes and caused about 26,000 deaths and 3000 injured. Recent catastrophic earthquakes (2004-2011) occurred in Asia, Europe and America have provided and renewed interest in question of the existence of precursory signals related to earthquakes. In these circumstances, the science community is struggling on how to provide early information related to the occurrence time of such events in order to reduce the loss of human life and property. Previous studies (Gotoh et al., 2002; Fraser-Smith et al., 1990; Freund et al., 1999; Hattori et al., 2006; Hayakawa \& Fujinawa, 1994; Hayakawa \& Molchanov, 2002; Kopytenko et al., 1994; Liu et al., 2004; Ouzounov et al., 2006; Parrot et al., 2007; Pulinets et al., 2004; Stanica \& M. Stanica, 2007; Stanica \& D.A. Stanica, 2010; Tramutoli et al., 2005; Tronin et al., 2004; Varotsos, 2005) have shown that there were precursory signals observed on the ground and in space associated with several earthquakes. In the last 10 years, the interdisciplinary group for Electromagnetic Study of Earthquakes and Volcanoes (EMSEV) have demonstrated that the existence of the electromagnetic earthquake precursors by terrestrial and satellite observations is not trivial, and it is necessary a wide international cooperation and several more years of research with primary focus in the following directions: (i) what is the possible generation mechanisms of the electromagnetic phenomena; and (ii) whether electromagnetic precursors systematically precede earthquakes. In this respect, taking into account that the seismic-active Vrancea zone, Romania is one of the "hot" subjects in the Eastern Europe, this paper is focused on the specific methodology able to emphasize the short-term electromagnetic (EM) precursory parameters, associated to intermediate depth earthquakes $(70-180 \mathrm{Km})$. We consider that one of the realistic mechanisms for triggering such events in the seismogenic volume can be the dehydration of rocks which make fluid-assisted faulting possible. The changes of electrical conductivity occurred before an earthquake, as a sequence of geodynamic processes 
associated with fluid migration through faulting system developed into and in the close vicinity of the seismogenic volume, could be detected by means of the anomalous behavior of the Bzn parameter taken throughout the frequency range less than $1.66 \mathrm{E}-2 \mathrm{~Hz}$ (Stanica \& M. Stanica, 2007; Stanica \& D.A. Stanica, 2010). According to the electromagnetic information acquired in 2009-2010 years correlated with seismic events, it is relieved that some days before an EQ occurred, the daily mean variation of the Bzn parameter have an anomalous behavior marked by a significant increase versus its normal distribution identified in non seismic conditions.

\section{Geodynamic models and possible mechanisms of intermediate depth earthquakes}

The seismic active Vrancea zone is situated at the curvature of the Carpathians and it is bounded on the north-east by the East European Platform, to southward by the Moesian Platform, and on the north-west by Transylvanian Basin (Fig.1).

The hypocenters of the intermediate depth earthquakes are concentrated within a very small seismogenic volume and they are much denser than any other mantle events of intracontinental origin known in the world. In the past century, 4 large seismic events have

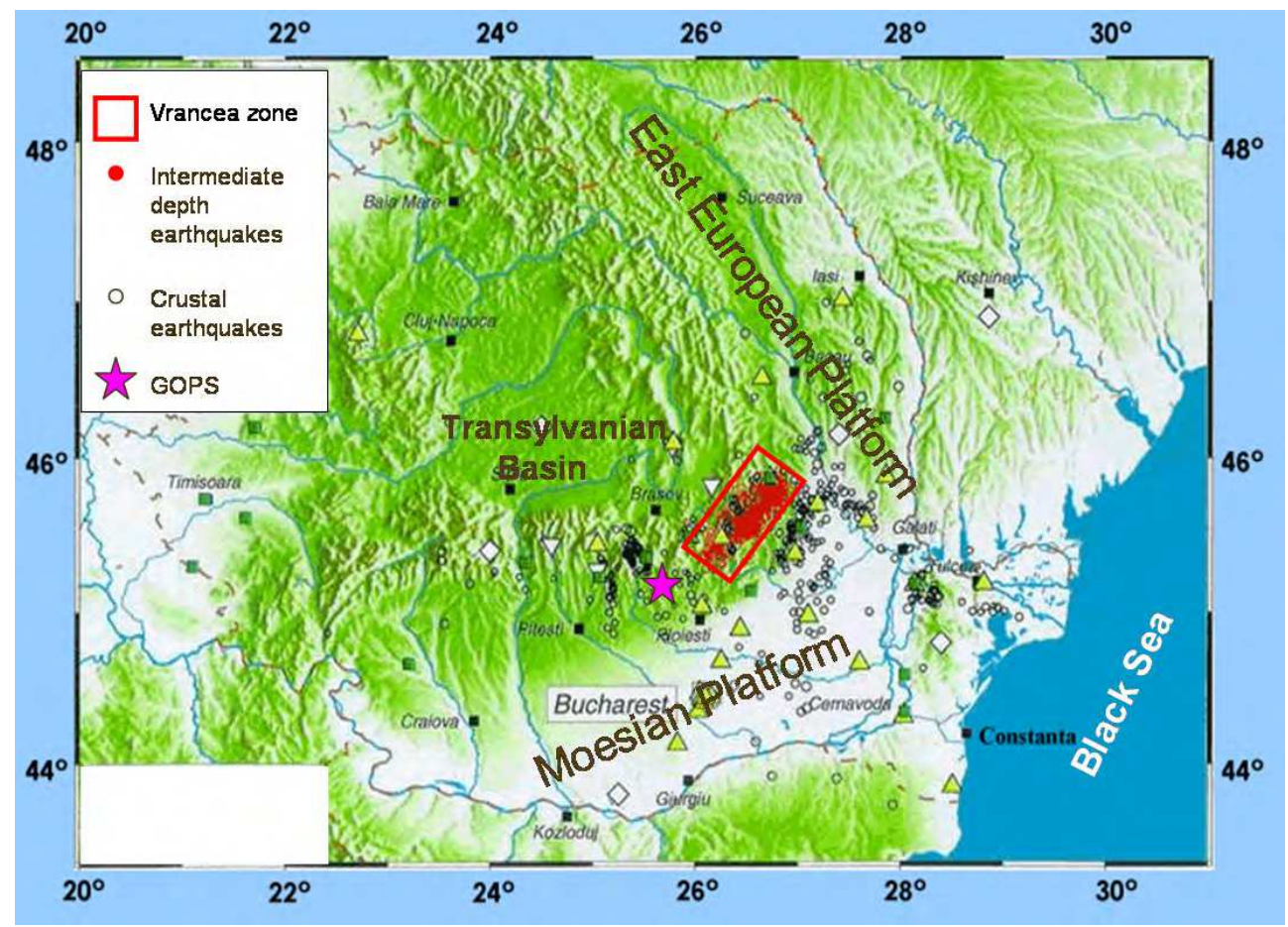

Fig. 1. Map of the seismic active Vrancea zone: crustal (white circles) and intermediate depth (red circles) epicenters of the earthquakes taken from ROMPLUS catalogue; pink star represents the Geodynamic Observatory Provita de Sus (GOPS) used as monitoring site of the earthquake precursors 
occurred in the intermediate depth range of 70 to $180 \mathrm{~km}$ (in 1940 with moment magnitude Mw7.7, in 1977 with Mw7.4, in 1986 with Mw7.1, and in 1990 with Mw 6.9) and all of them cause destruction in Bucharest, the capital city of Romania, and shake central and eastern European cities several hundred kilometers away from their epicenters.

Several geodynamic models related to the triggering mechanism of the intermediate depth earthquakes have been elaborated in this area. Oncescu (1984) and Oncescu at al., (1984) proposed a double subduction model on the basis of 3-D seismic tomographic images: in their interpretation, the intermediate-depth earthquakes are generated within a vertical surface separating the sinking slab from stable lithosphere.

Trifu \& Radulian (1989), analyzing the seismic behavior of the Vrancea zone, proposed a model based on the existence of two active zones located at depths of 80-110 km and 120-170 $\mathrm{km}$. Both zones are characterized by local stress inhomogeneities capable of generating large earthquakes.

Khain \& Lobkosky (1994) suggest that the Vrancea zone results from delamination processes occurred during continental collision and lithosphere sinking into the mantle.

Linzer (1996) explains the nearly vertical position of the Vrancea slab as the final rollback stage of a small fragment of oceanic crust.

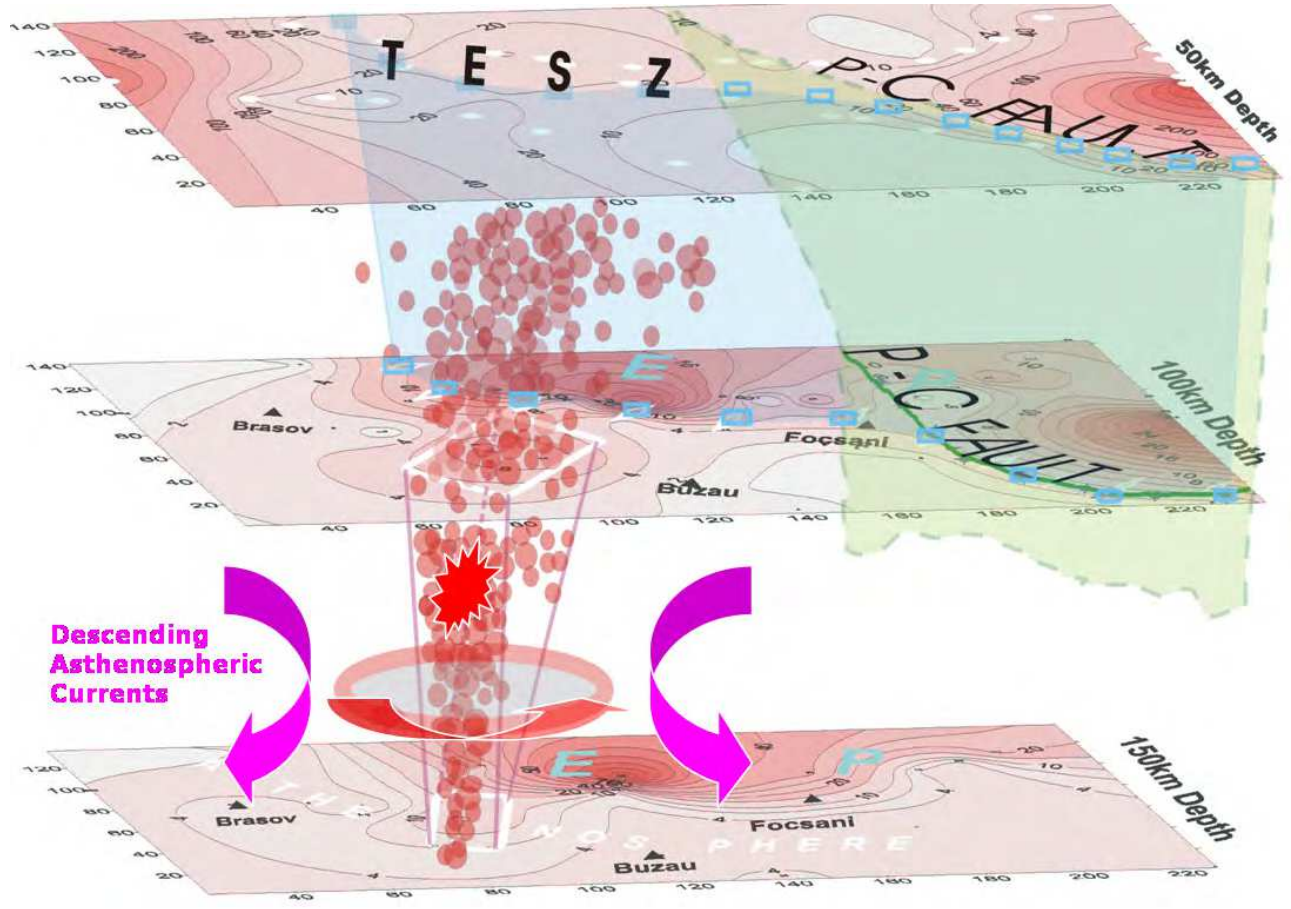

Fig. 2. 3D resistivity tomographic image at sub-crustal level in the seismic active Vrancea zone: red circles are intermediate depth earthquakes; blue square delineate the TransEuropean Suture Zone (M. Stanica et al., 1999); green line is Peceneaga-Camena fault (P-C fault); pink arrows show the direction of the asthenospheric currents; red arrow shows the direction of the torsion process of the relic slab 
Sperner, B., the Collaborative Research Center [CRC] 461 Team, (2005), taking into consideration that the geometry of the subduction zone was not unequivocally defined, proposed four possible configurations for the Vrancea zone: (i) subduction beneath the suture zone; (ii) subduction beneath the fore deep area; (iii) two interacting subduction zones, and (iv) subduction beneath the suture, followed by delamination.

Various types of slab detachment or delamination have been proposed to explain the present-day seismic images of the descending slab (Girbacea \& Frisch, 1998; Gvirtzman, 2002; Sperner et al., 2001; Wortel \& Spakman, 2000).

Viscous flows due to the sinking seismogenic slab together with dehydration-induced faulting can be considered as possible triggering mechanism explaining the intermediatedepth seismicity in Vrancea (Ismail-Zadeh et al., 2000)

Stanica et al., (2004) show, on the base of the three-dimensional (3D) resistivity tomographic image carried out using magnetotelluric data, that the possible triggering mechanism of the intermediate-depth earthquakes in the Vrancea zone may be the rock response to the active torsion processes sustained by the descending asthenospheric currents and the irregular shape of the relic slab. In their opinion, this torque effect may generate the increase shear stress and drive faulting process within the rigid slab (Fig.2).

\section{Generation mechanisms and theoretical base of the electromagnetic precursors to earthquakes}

\subsection{Possible generation mechanisms of electromagnetic precursors}

This paper is not intended to present an exhaustive analysis of all of literature published in this field. Instead, we have tried to provide only some representative hypothetic mechanisms related to the electromagnetic precursors to earthquakes.

The theory of semiconductors launched by Freund (2000) is considered the most comprehensive one. According to this theory, the solid rocks (e.g. granites) begin to crack under the action of a stress exceeding their elasticity limit, what leads to a release of electric charges. These charges, carried by water moving through the rocks fissures, generate currents of high amperage that, in their turn, create disturbances of the magnetic field and, also, infrared signature in the bands of $8 \mu \mathrm{m}$ and $11 \mu \mathrm{m}$, when the charges are neutralized at the surface of the Earth.

In accordance with this theory, to have seismo-electric signals it is necessary that a few compulsory conditions to be fulfilled:

- Presence of major tectonic accidents able to produce an important stress;

- Existence of quartz or rocks with a rich content of quartz;

- Fluid carrying electric charges through porous rock what generates electric currents that lead to disturbances of the magnetic field.

The resistivity of porous rocks is changed as a function of compression and shearing (Brace et al., 1965) and may be measured by using passive experiments (magnetotelluric method), or experiments with active methods (Park et al., 1993).

Revol et al., (1977) have shown that the magnetic properties of rocks are changed depending on the applied stress and are associated to the changes of stress emphasized on fault rupture, what produces oscillations of the magnetic field of a few nT (Johnston, 1978, 1997); this mechanism is due to the piezomagnetic effect.

When a conductive fluid is forced to flow close to a surface with stationary electric charges, an electrokinetic effect appears generating currents that start to flow either through fluid, or 
through the surrounding rock, what, in conditions imposed by real crustal parameters, may create surface magnetic fields of a few nT (Fenoglio et al., 1995).

Another theory supposes the generation of the magnetic signal either by conductive fluid flowing in presence of the magnetic field of the Earth, or by magnetohydrodynamic conversion of the seismic signal into an electric signal during the propagation through a conductive medium (Molchanov et al., 2001). While these mechanisms were proved in laboratory conditions, it is unclear, yet, how this process takes place in conditions rather similar to those specific to the Earth, owing to the lack of measurements in active fault zones.

\subsection{Theoretical base of the electromagnetic precursors}

At the Earth surface the vertical geomagnetic component $(\mathrm{Bz})$ is entirely secondary field and its existence is an immediate indicator of lateral inhomogeneity. For a two-dimensional (2D) structure, the vertical geomagnetic component $(\mathrm{Bz})$ is produced essentially by the horizontal geomagnetic component perpendicular $\left(\mathrm{B}_{\perp}\right)$ to geoelectric structure orientation and, consequently, the normalized Bzn function defined as:

$$
\operatorname{Bzn}(f)=\frac{B z(f)}{B_{\perp}(f)}
$$

should be time invariant in non geodynamic conditions (Ward et al., 1970), but it becomes unstable due to the geodynamic processes and, therefore, it could be used as a precursory parameter of the intermediate depth seismic activity (Stanica and D.A. Stanica, 2010).

In order to explain cause (earthquake) - effect (anomalous Bzn) relationship, we introduce the following equations:

$$
\rho z(f)=\frac{0.2}{f}\left|\frac{E_{f}(f)}{B z(f)}\right|^{2}
$$

where: $\rho z$ is vertical resistivity $\left[\Omega m=\mathrm{VmA}^{-1}\right], \mathrm{f}$ is the frequency $[\mathrm{Hz}]$ and the $\mathrm{E}_{\|}$is the electric field parallel to strike $\left[\mathrm{Vm}^{-1}\right], \mathrm{Bz}$ is the vertical component of the magnetic induction [Tesla $(\mathrm{T})=\mathrm{V} \mathrm{s} \mathrm{m}^{-2}$.

Also, it is possible to write the relation:

$$
\rho_{\|}(f)=\frac{0.2}{f}\left|\frac{E_{\|}(f)}{B_{\perp}(f)}\right|^{2},
$$

where: $\rho \|$ is the resistivity parallel to strike $[\Omega \mathrm{m}], B_{\perp}$ is the component of the magnetic induction perpendicular to strike

[Tesla $\left.(\mathrm{T})=\mathrm{V} \mathrm{s} \mathrm{m}^{-2}\right]$.

From the relations (2) and (3) we may estimate the normalized function Bzn (f), in terms of resistivities as follows:

$$
|\operatorname{Bzn}(\mathrm{f})|=\sqrt{\frac{\rho_{\|}(\mathrm{f})}{\rho z(f)}}
$$

This estimation of Bzn is in error for non two-dimensional geoelectrical structure. 


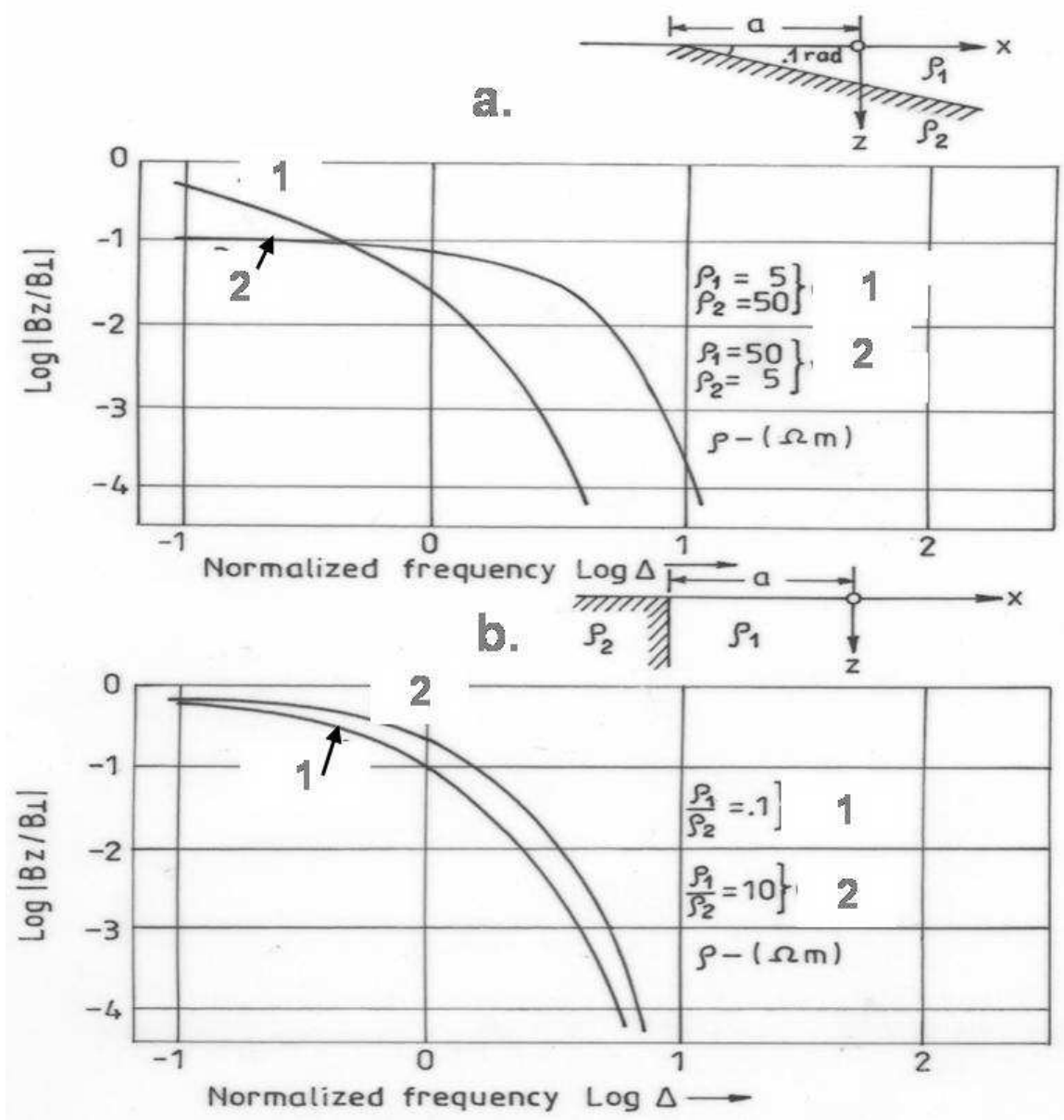

Fig. 3. Bzn distribution versus normalized frequency for sloping interface (a.) and vertical contact (b.): $\Delta=\mathrm{a} / \delta_{1}$

The relation (4) demonstrates that normalized function Bzn could be linked to the resistivity/conductivity variation along the faulting systems acting as high sensitive path (represented by the Carpathian electrical conductivity anomaly) through the lithosphere and its right part lead to the normalized resistivity defined as:

$$
\rho n(f)=\frac{\rho_{\|}(\mathrm{f})}{\rho z(f)}
$$

Approximate field solutions were computed for two simple 2D geoelectric structures to illustrate the robustness of the relation (1). Solutions for the sloping interface and vertical contact models were obtained using finite element code (Wannamaker et al., 1986) and the results are presented in Fig. 3. These models represent two extremes in dipping angle of the interface and similarity in the properties of the normalized function Bzn obtained for the 
model (Fig.3, b.) is of interest in selecting the site (GOPS) for continuous monitoring of the geomagnetic field. The normalized frequency scale $(\Delta)$ is proportional to distance along the $x$-axis and inverse-proportional to penetration depth $\left(\delta_{1}\right)$ in medium of resistivity $\rho_{1}$. The electromagnetic skin depth or penetration depth is given by:

$$
\delta_{1}[\mathrm{~km}]=\frac{1}{2 \Pi} \sqrt{\frac{10 \rho_{1}[\Omega \mathrm{m}]}{f[\mathrm{~Hz}]}}
$$

\section{Electromagnetic (EM) methodology and results}

\subsection{Electromagnetic data collection}

As we have seen in relation (1), Bzn could be used as precursory parameter of seismic event by measuring the vertical geomagnetic component (Bz) and horizontal component perpendicular to the strike $\left(B_{\perp}\right)$ which have been collected at the Geodynamic Observatory Provita de Sus (GOPS), placed on the Carpathian electrical conductivity anomaly (CECA). This anomaly is delineated by the Wiese induction arrows, and it can represent a zone of partial melting or of hot highly-mineralized fluids in sedimentary layers, formed at the collisional limit between the both platforms (East European and Moesian) with Carpathian Alpine structures (Fig.4). It is also quit possible that these two varieties of fluid anomalies to co-exist and gradually flow one into another, as indicated by the fact that geoelectric parameters remain fairly constant throughout its entire length (Pinna et al., 1993, Rokityansky \& Ingerov, 1999).

Induction arrows are vector representations of the ratio of vertical to horizontal magnetic field components. Since vertical magnetic fields are generated by lateral conductivity gradients, induction arrows map can be used to infer the presence, or absence of lateral variation of conductivity/resistivity. In the Wiese convection (Wiese, 1962) the vectors point away from the conductivity anomaly generated by anomalous internal concentrations of current, while in the Parkinson convection (Parkinson, 1959), the vectors point towards anomalous internal concentrations of current. Thus, insulator-conductor boundaries extended through a 2D geoelectrical structure (like CECA) give rise to induction arrows that orientate perpendicular to their geoelectrical strike, and have magnitude proportional to the intensity of anomalous current concentration (Jones \& Price, 1970), which are in turn determined by the magnitude of conductivity gradient.

In our methodology, it was also supposed that pre-seismic conductivity changes, due to the fluid migration through faulting system, may generate changes of the normalized function Bzn, having magnitude proportional to the intensity of anomalous current concentrations through CECA.

The Geodynamic Observatory Provita de Sus (Fig.1) is located at about $100 \mathrm{~km}$ towards south-west of seismic active Vrancea zone and the criteria of selection as monitoring site are:

- $\quad$ Existence of logistic base able to supply optimal EM data;

- Placement on the Carpathian electrical conductivity anomaly where, ideally, the condition for a 2D type geoelectric structure is fulfilled (Fig. 4);

- Real time wireless data transfer to the central office (Institute of Geodynamics, Bucharest).

In order to select the frequency range where the relation (1) is valid (i.e., existence of a 2D geoelectrical structure and its strike orientation), as a first step in our EM methodology, at the GOPS we made a magnetotelluric sounding using the magnetotelluric (MT) equipment 
GMS-06 (METRONIX - Germany). This geophysical system has 5 channels (two electric Ex, Ey and three magnetic Bx, By, Bz components), 24 bit resolution, GPS, two frequency ranges (LF: 4096sec.-1kH; HF=0.5kH-10kH) and for data processing "MAPROS" software packages.

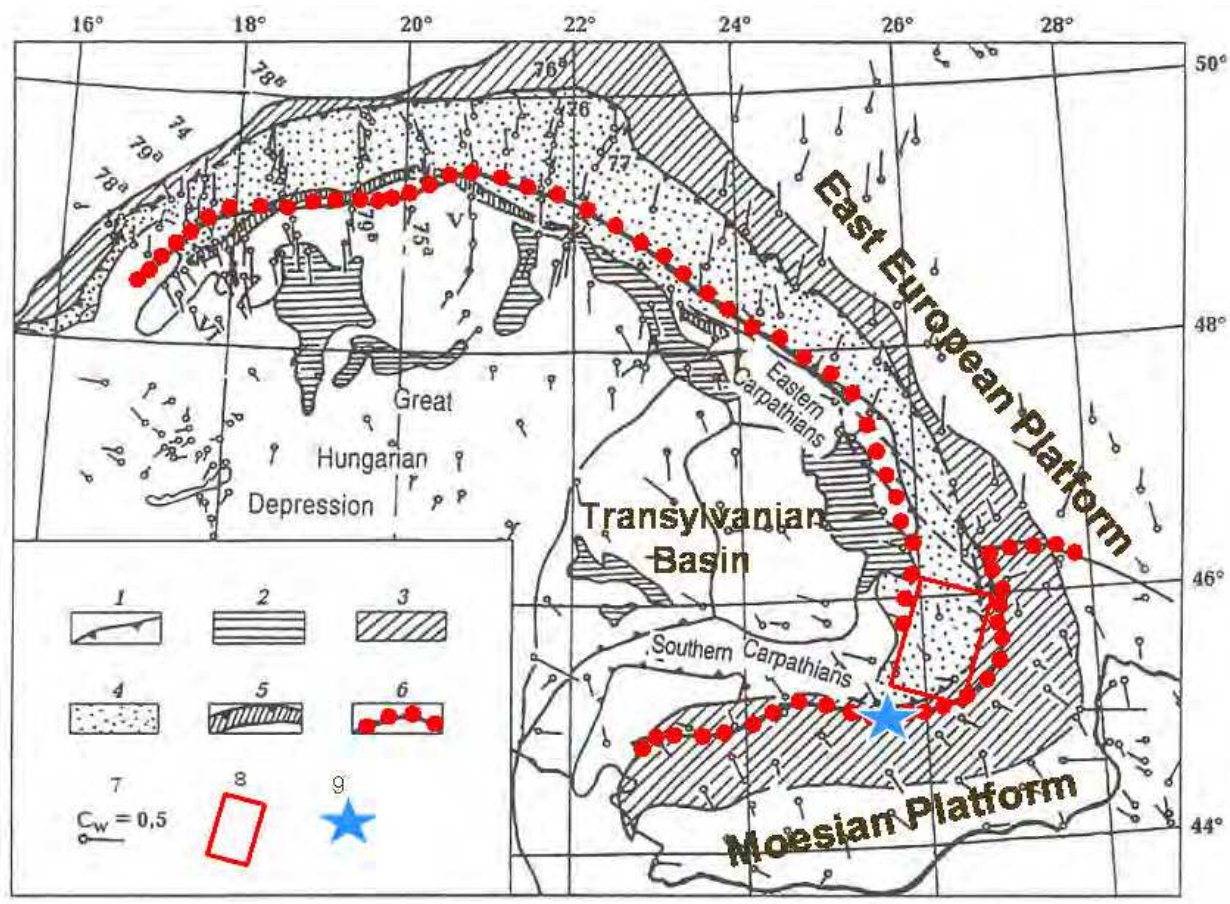

Fig. 4. Carpathian electrical conductivity anomaly and Wiese induction arrows on a tectonic sketch map: 1) main boundaries and fractures (over thrusts) of regional structures; 2)

Neogene volcanic rocks; 3) Carpathian fore-deep; 4) Carpathian flysch nape system; 5) Piena and Marmarosh cliff belt; 6) Carpathian electrical conductivity anomaly (CECA); 7) Wiese induction vectors magnitude; 8) seismic active Vrancea zone (intermediate-depth earthquakes); 9) Geodynamic Observatory Provita de Sus (GOPS) used for the electromagnetic data collection (Modified after Rokityansky \& Ingerov, 1999)

It is well known that the magnetotelluric (MT) method is a passive technique that involves measuring fluctuations of natural electric (E) and magnetic (B) fields in orthogonal directions at the surface of the Earth (Kaufman, \& Keller, 1981). The orthogonal components of the horizontal electric (Ex, Ey) and magnetic $(\mathrm{Bx}, \mathrm{By})$ fields are related by the complex impedance tensor, $\mathrm{Z}$ :

$$
\left(\begin{array}{l}
E x \\
E y
\end{array}\right)=\left(\begin{array}{ll}
Z x x & Z x y \\
Z y x & Z y y
\end{array}\right)\left(\begin{array}{c}
B x \\
B y
\end{array}\right) \text {, or } E=Z B
$$

Where: Zxx, Zxy, Zyx, Zyy are elements of the impedance tensor [VA-1]

For a $2 \mathrm{D}$ structure, in which the conductivity varies along one horizontal direction as well as with depth, the following relations are fulfilled: 


$$
\begin{aligned}
& Z x x=-Z y y \\
& Z x y \neq-Z y x
\end{aligned}
$$

Using single site magnetotelluric impedance tensor decomposition technique (Bahr, 1988), it was possible to identify the following two parameters: skewness and strike orientation. The skewness is a dimensionality parameter of the impedance tensor, defined as:

$$
\text { Skew }=\left|\begin{array}{|l}
\mid Z x x+Z y y \\
\mid Z x y+Z y x
\end{array}\right|
$$

This parameter should be less than 0.3 to interpret the structure as $2 \mathrm{D}$.

The tensor impedance from relation (7) can be rotated to obtain the strike orientation of the 2D geoelectrical structure using the relation:

$$
a=\frac{1}{4} \arctan \frac{2 \operatorname{Re}(Z x y+Z y x)(\overline{Z x x-Z y y})}{\left(|Z x x-Z y y|^{2}-|Z x x+Z y x|^{2}\right)}
$$

Where: $\alpha$ (strike) is rotation angle $\left[{ }^{0}\right]$.

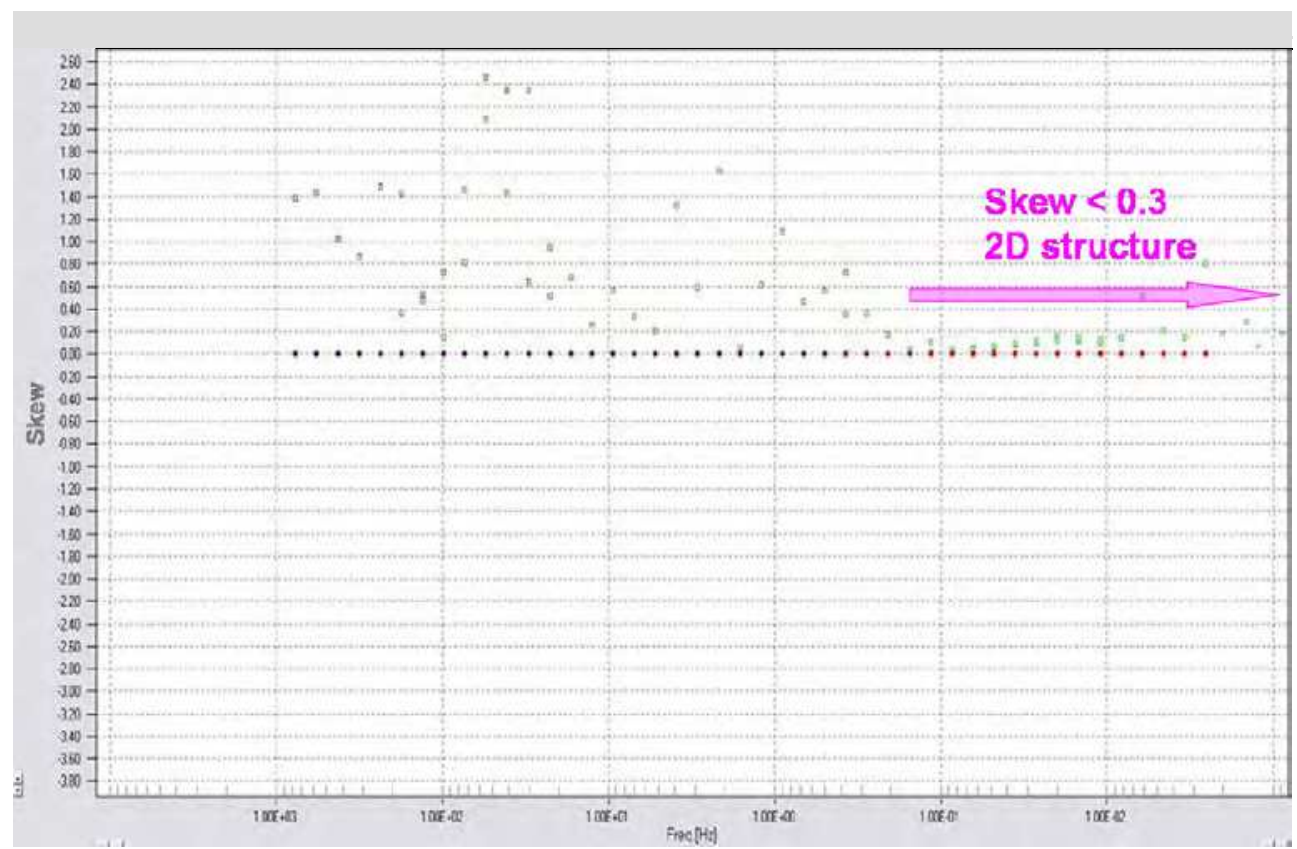

Fig. 5. Skewness parameter versus frequency $(\mathrm{Hz})$ : pink arrow delineates the frequency range for $2 \mathrm{D}$ structure

The MAPROS software packages include all these mathematical relations presented above and have been applied to MT sounding carried out at GOPS. This program performs the following basic tasks: 
- Real time data acquisition and processing;

- Robust estimation of the magnetotelluric transfer functions;

- Real time display of time series and all important electromagnetic parameters $\left(\rho_{\perp}, \rho \|\right.$, skewness and strike, etc).

Thus, on the base of MT results, a 2D geoelectrical structure has been identified on the frequency range less than $1.66 \mathrm{E}-2 \mathrm{~Hz}$ where skewness < 0.3 (Fig.5) and average strike orientation is $\mathrm{N}^{\circ} 6^{\circ} \mathrm{E}$ (Fig.6). This frequency range is also associated with the intermediatedepth earthquakes interval $(70-180 \mathrm{~km})$ where EM precursors are generated.

These results confirm, once more, that the CECA's geoelectrical structure is of 2D type with strike orientation approximately east-west, and forms not only a tectonic boundary between Moesian Platform and Carpathian Alpine structures, but also represents a peculiar conducting channel extended to the seismic active Vrancea zone (Fig.4).

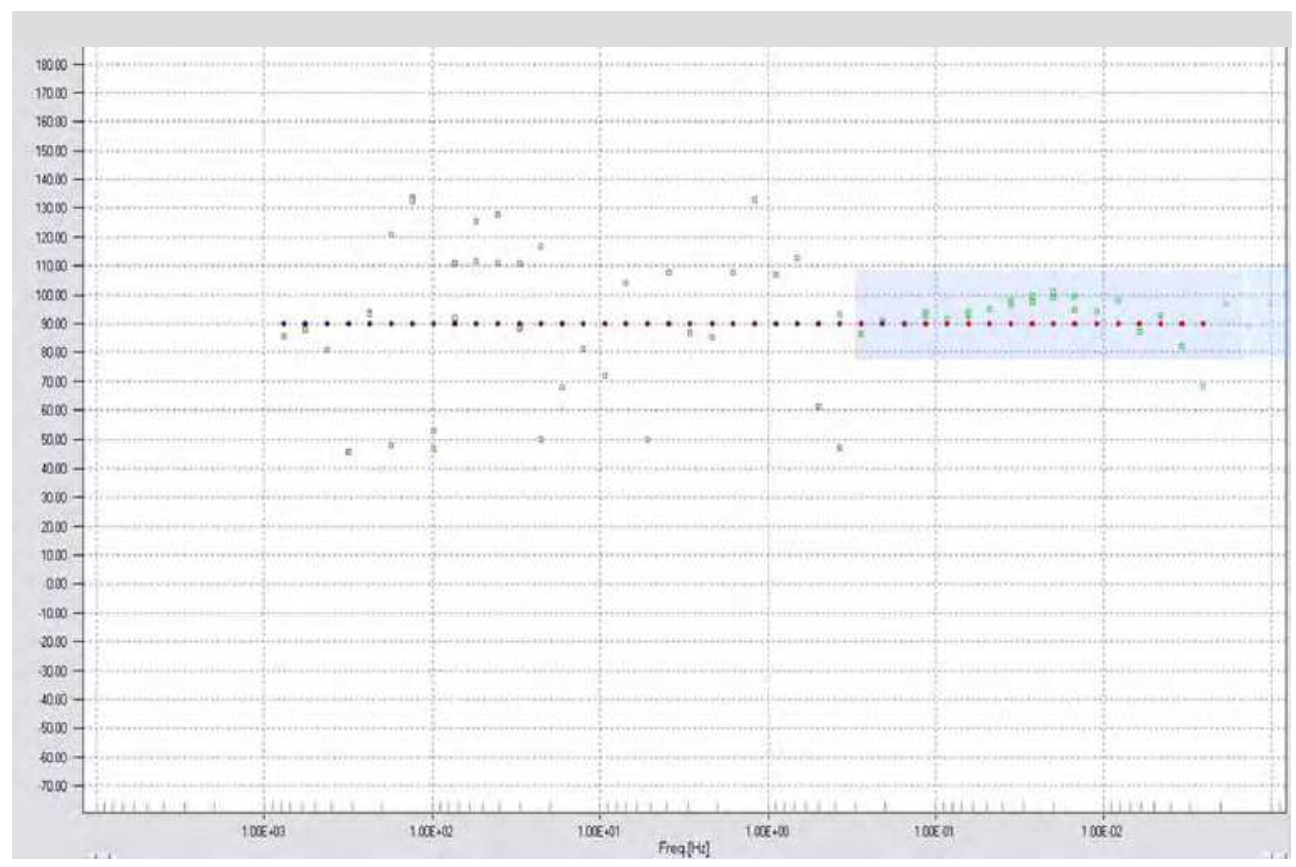

Fig. 6. Strike orientation (degrees) versus frequency (Hz): blue rectangle delineates the frequency range for $2 \mathrm{D}$ structure with average strike orientation of $\mathrm{N} 96^{\circ} \mathrm{E}$

The next step in our study was to realize a continuous monitoring of the geomagnetic components $\left(\mathrm{B}_{\perp}, \mathrm{B} \|, \mathrm{Bz}\right)$ using the acquisition module MAG-03 DAM (Bartington-England), with 6 channels, 24 bit resolution and three axis magnetic field sensor MAG-03 MSL (frequency range: $\mathrm{DC}-1 \mathrm{kHz}$ ). In order to obtain $\mathrm{B}_{\perp}$ component of the geomagnetic field, one of the horizontal components of the three axis magnetic sensor must be orientated perpendicular to strike. The parameters of the data acquisition card are under software control and additional program collects information at each five seconds and stored them, every 60 seconds (Table.1), on the PC HD. Using the wireless connection, all the data are transferred from GOPS to the central unit, placed at the Institute of Geodynamics in Bucharest, for real-time data processing and analysis (Fig.7). 


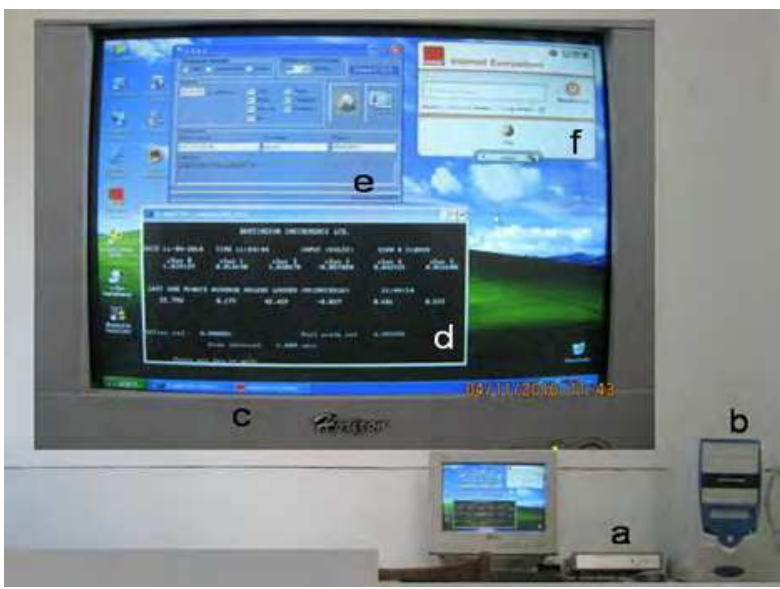

Fig. 7. Monitoring system of the geomagnetic components (Bx, By and $\mathrm{Bz}$ ) and real time data transfer : acquisition module MAG-03DAM (a); computer (b) for data storage; monitor (c) for real time geomagnetic data display $(\mathrm{d})$; data transfer program $(\mathrm{e})$; wireless connection (f)

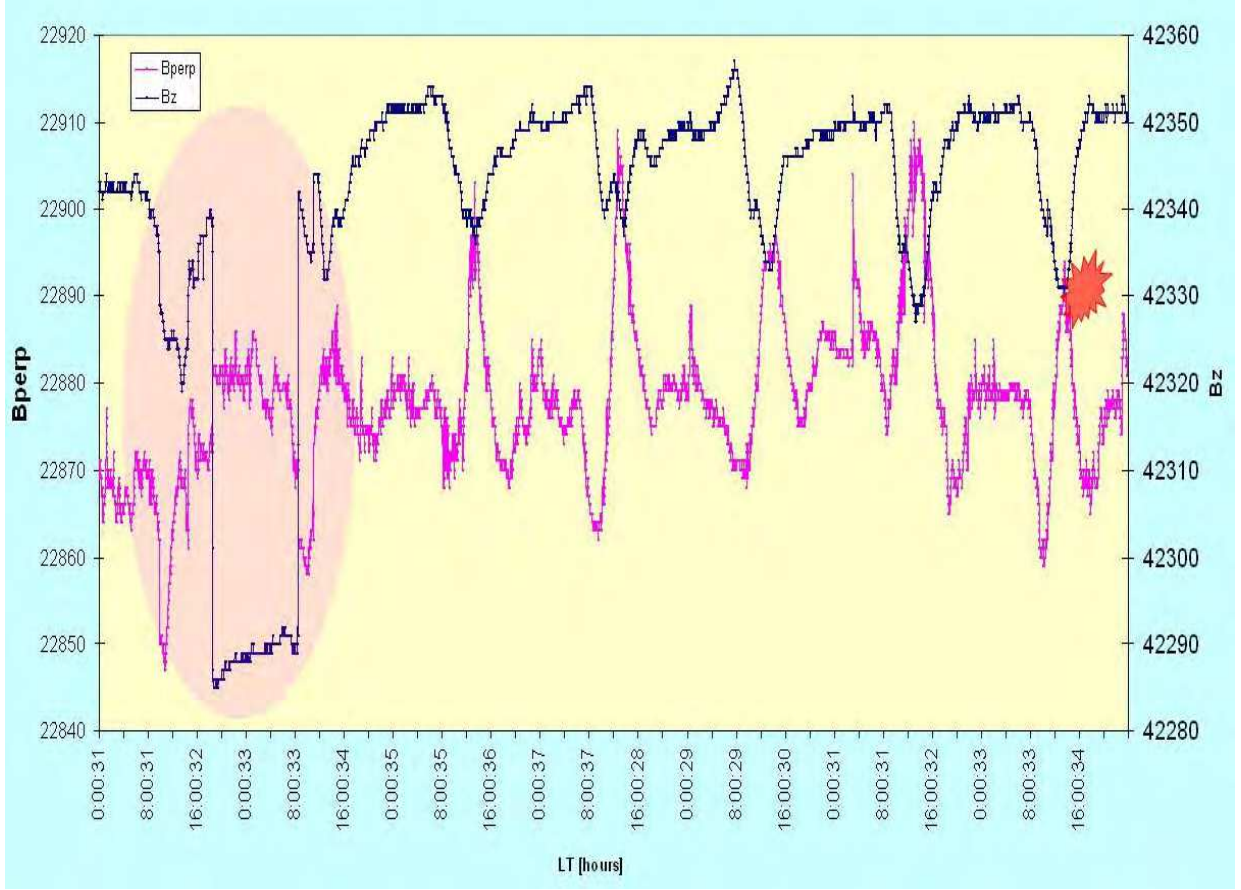

Fig. 8. Geomagnetic time series (Bperp and Bz) recorded at the GOPS for 7 days interval (April19- April 25, 2009); Bperp is $B_{\perp}$; red star is earthquake of M5.0; pink ellipse marks a pre-seismic disturbance of the vertical component $(\mathrm{Bz})$ of geomagnetic field (lead time is about 6 days before the earthquake). 


\begin{tabular}{|c|c|c|c|c|c|c|c|}
\hline Date & Time [s] & $B_{\perp}[\mu \mathrm{T}]$ & $\mathbf{B}_{\|}[\mu \mathrm{T}]$ & $\mathrm{Bz}[\mu \mathrm{T}]$ & Bzn & $\begin{array}{l}\text { Bzn average } \\
\text { (1day data) }\end{array}$ & STDEV \\
\hline $7 / 17 / 2009$ & 0:00:37 & 22.869 & 0.22 & 42.367 & 1.852595 & 1.852561 & 0.000281 \\
\hline $7 / 17 / 2009$ & 0:01:37 & 22.869 & 0.22 & 42.367 & 1.852595 & & \\
\hline $7 / 17 / 2009$ & $0: 02: 37$ & 22.869 & 0.22 & 42.367 & 1.852595 & & \\
\hline $7 / 17 / 2009$ & 0:03:37 & 22.868 & 0.22 & 42.367 & 1.852676 & & \\
\hline $7 / 17 / 2009$ & 0:04:37 & 22.868 & 0.22 & 42.367 & 1.852676 & & \\
\hline $7 / 17 / 2009$ & 0:05:37 & 22.868 & 0.221 & 42.367 & 1.852676 & & \\
\hline $7 / 17 / 2009$ & $0: 06: 37$ & 22.869 & 0.22 & 42.367 & 1.852595 & & \\
\hline $7 / 17 / 2009$ & $0: 07: 37$ & 22.868 & 0.22 & 42.367 & 1.852676 & & \\
\hline $7 / 17 / 2009$ & 0:08:37 & 22.868 & 0.221 & 42.367 & 1.852676 & & \\
\hline $7 / 17 / 2009$ & 0:09:37 & 22.868 & 0.22 & 42.367 & 1.852676 & & \\
\hline $7 / 17 / 2009$ & $0: 10: 37$ & 22.868 & 0.22 & 42.367 & 1.852676 & & \\
\hline $7 / 17 / 2009$ & 0:11:37 & 22.869 & 0.221 & 42.368 & 1.852639 & & \\
\hline $7 / 17 / 2009$ & $0: 12: 37$ & 22.868 & 0.22 & 42.368 & 1.85272 & & \\
\hline $7 / 17 / 2009$ & $0: 13: 37$ & 22.868 & 0.221 & 42.368 & 1.85272 & & \\
\hline $7 / 17 / 2009$ & $0: 14: 37$ & 22.869 & 0.221 & 42.368 & 1.852639 & & \\
\hline $7 / 17 / 2009$ & $0: 15: 37$ & 22.868 & 0.22 & 42.367 & 1.852676 & & \\
\hline $7 / 17 / 2009$ & $0: 16: 37$ & 22.868 & 0.221 & 42.367 & 1.852676 & & \\
\hline $7 / 17 / 2009$ & $0: 17: 37$ & 22.869 & 0.221 & 42.367 & 1.852595 & & \\
\hline $7 / 17 / 2009$ & $0: 18: 37$ & 22.868 & 0.221 & 42.367 & 1.852676 & & \\
\hline $7 / 17 / 2009$ & $0: 19: 37$ & 22.869 & 0.221 & 42.367 & 1.852595 & & \\
\hline $7 / 17 / 2009$ & $0: 20: 37$ & 22.869 & 0.221 & 42.368 & 1.852639 & & \\
\hline $7 / 17 / 2009$ & $0: 21: 37$ & 22.869 & 0.221 & 42.368 & 1.852639 & & \\
\hline $7 / 17 / 2009$ & $0: 22: 37$ & 22.869 & 0.221 & 42.368 & 1.852639 & & \\
\hline $7 / 17 / 2009$ & $0: 23: 37$ & 22.869 & 0.221 & 42.368 & 1.852639 & & \\
\hline $7 / 17 / 2009$ & $0: 24: 37$ & 22.87 & 0.221 & 42.368 & 1.852558 & & \\
\hline $7 / 17 / 2009$ & $0: 25: 37$ & 22.869 & 0.221 & 42.368 & 1.852639 & & \\
\hline $7 / 17 / 2009$ & $0: 26: 37$ & 22.869 & 0.221 & 42.367 & 1.852595 & & \\
\hline $7 / 17 / 2009$ & $0: 27: 37$ & 22.869 & 0.221 & 42.367 & 1.852595 & & \\
\hline $7 / 17 / 2009$ & $0: 28: 37$ & 22.869 & 0.221 & 42.367 & 1.852595 & & \\
\hline $7 / 17 / 2009$ & 0:29:37 & 22.869 & 0.221 & 42.367 & 1.852595 & & \\
\hline $7 / 17 / 2009$ & $0: 30: 37$ & 22.869 & 0.221 & 42.368 & 1.852639 & & \\
\hline $7 / 17 / 2009$ & 0:31:37 & 22.869 & 0.221 & 42.367 & 1.852595 & & \\
\hline $7 / 17 / 2009$ & $0: 32: 37$ & 22.869 & 0.222 & 42.367 & 1.852595 & & \\
\hline $7 / 17 / 2009$ & $0: 33: 37$ & 22.869 & 0.222 & 42.367 & 1.852595 & & \\
\hline $7 / 17 / 2009$ & $0: 34: 37$ & 22.868 & 0.222 & 42.367 & 1.852676 & & \\
\hline $7 / 17 / 2009$ & $0: 35: 37$ & 22.869 & 0.222 & 42.367 & 1.852595 & & \\
\hline $7 / 17 / 2009$ & $0: 36: 37$ & 22.868 & 0.221 & 42.367 & 1.852676 & & \\
\hline $7 / 17 / 2009$ & $0: 37: 37$ & 22.869 & 0.221 & 42.367 & 1.852595 & & \\
\hline $7 / 17 / 2009$ & $0: 38: 37$ & 22.869 & 0.221 & 42.367 & 1.852595 & & \\
\hline $7 / 17 / 2009$ & 0:39:37 & 22.869 & 0.221 & 42.367 & 1.852595 & & \\
\hline $7 / 17 / 2009$ & $0: 40: 37$ & 22.868 & 0.221 & 42.367 & 1.852676 & & \\
\hline $7 / 17 / 2009$ & $0: 41: 37$ & 22.869 & 0.221 & 42.367 & 1.852595 & & \\
\hline $7 / 17 / 2009$ & $0: 42: 37$ & 22.868 & 0.222 & 42.367 & 1.852676 & & \\
\hline
\end{tabular}

Table 1. Geomagnetic time series $B_{\perp}, B_{\|}$and Bz recorded on July 17th 2009 (42 minutes record): Bzn average is computed for 1day data; STDEV of the Bzn average. 
The geomagnetic time series recorded at the GOPS for 7 days interval (April19- April 25, 2009), including the occurrence time of the earthquake of M5.0 (April 25), are presented in Fig. 8. The pre-seismic disturbance of the vertical component (Bz) occurred about 6 days before earthquake. But, as we have seen later on, this disturbance is masked by the superposition effect started on March 9, 2009.

\subsection{Results}

In this paper, daily mean distribution of the normalized function Bzn and its standard deviation are performed in the frequency range less than $1.666 \mathrm{E}-2 \mathrm{~Hz}$, where $2 \mathrm{D}$ structural condition is fulfilled. The concept of this analysis is based on the idea that signal associated with solar-terrestrial origin is constant, according to relation (1), while lithospheric origin signal from the underground current flowing along the CECA is considered to have a vertical component (see fig.8). With the other words, the normalized function Bzn shows a small and certain value for its normal trend (in non seismic condition) and increased values in pre-seismic conditions.

To assess the robustness of the presented methodology, some examples of Bzn distribution acquired in a span of about two years (2009 -2010) are shown in correlation with the intermediate depth earthquakes, with magnitude $(\mathrm{Mw})$ higher than 4.0 (Richter scale), selected from the catalogue issued by National Institute of the Earth Physics-Bucharest.

The first particular case of the Bzn distribution correlated with the both standard deviation (STDEV) and intermediate depth earthquakes, within the interval January 16 - May 11, 2009 is shown in Fig. 9.

The Bzn distribution emphasizes two domains, the first one, with normal values of about 1.842 on the interval January16 - March 8 and second one, on March 9- May 11 interval, having values between 1.850-1.856, and all earthquakes are marked by vertical arrows.

Average value of 1.842 , associated with earthquakes of $M<3.3$ occurred on the interval January 16 - March 8 represents the threshold limit between the so called "normal trend" of Bzn and its second anomalous domain, which started on March 9, which may represent a superposition effect of the four earthquake of M4.0 (March 21), M4.1 (April 12), M5.0 (April 25) and M5.0 (May 11).

The earthquake of magnitude 5.0 was triggered in the Vrancea zone, at $109 \mathrm{~km}$ depth, on April 25 at 20:18:48 (local time), being felt in Bucharest and over a large area extended from the epicentral zone towards NE and SW directions, corresponding with the fault plane orientation of the focal mechanism.

Similar results have been obtained in the Bzn distribution (Fig.10) on the interval February 1-March 31, 2010, where the threshold limit of about 1.842 separates also two domains, one with normal trend (earthquakes of $\mathrm{M}<3.4$ ) extended on the interval February 01- February 18, and anomalous one, on the interval February 21- March 31, having Bzn values between 1.850 1.855 . The last interval could be correlated with the superposition effect produced by the two earthquakes of M4.2, and the pre-seismic lead time is about 10 days before the first earthquake of M4.2 occurred.

Figures 11 and 12 depict results of Bzn distribution observed at GOPS on the two intervals May 28 - August 26, 2009 and the whole September month, 2009.

Figure 11 reveals three anomalous domains of Bzn which may be related to 5 earthquakes with magnitude larger than 4 . First domain, extended on the interval June 4 - July 10, is 
characterized by enhanced values of Bzn comprised between 1.852 and 1.854, and may be related to the superposition effect generated by the two earthquakes of M3.9 (June 20) and M4.0 (June 27). Pre-seismic increased values of Bzn are extended on 16 days interval for this group of earthquakes.

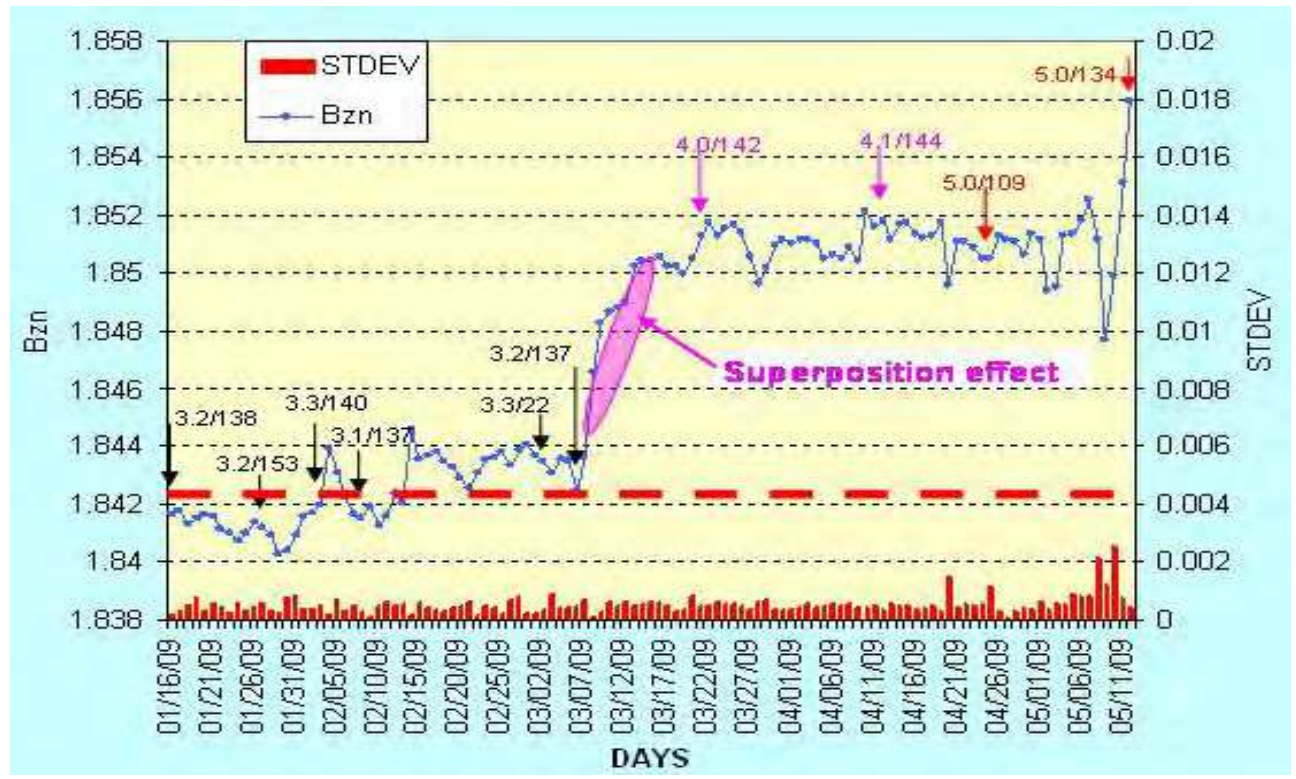

Fig. 9. Bzn and STDEV distributions at the GOPS, within the interval January 16 - April 30, 2009; vertical arrows are earthquakes and ratio 5.0/109 is the magnitude/hypocenter depth of earthquake in $[\mathrm{km}]$; dashed red line is threshold limit between normal trend and anomalous behaviour of the normalized function Bzn

The second anomalous domain, with an average value of Bzn of about 1.855, is extended on the interval July 14 - August 7 and reflects also superposition effect of the two earthquakes of magnitude 5.1 and 5.2, occurred on July 24 and August 5, respectively. The pre-seismic superposition effect of the Bzn started on July 15 and is developed in 9 days interval up to 
the occurrence of M5.1 earthquake (July 24). In the last anomalous domain (August 11August 26), the normalized function Bzn has values between $1.853-1.454$ and could be associated with the two earthquakes of M4.1 occurred on August 17 and 26. Here, the preseismic occurrence interval is of about 7 days.

Figure 12 illustrates the Bzn distribution for September 2009, where similar pre-seismic characteristics are observed. Thus, enhanced values of Bzn are correlated with the increased values of earthquake magnitudes and decreased foci depth.

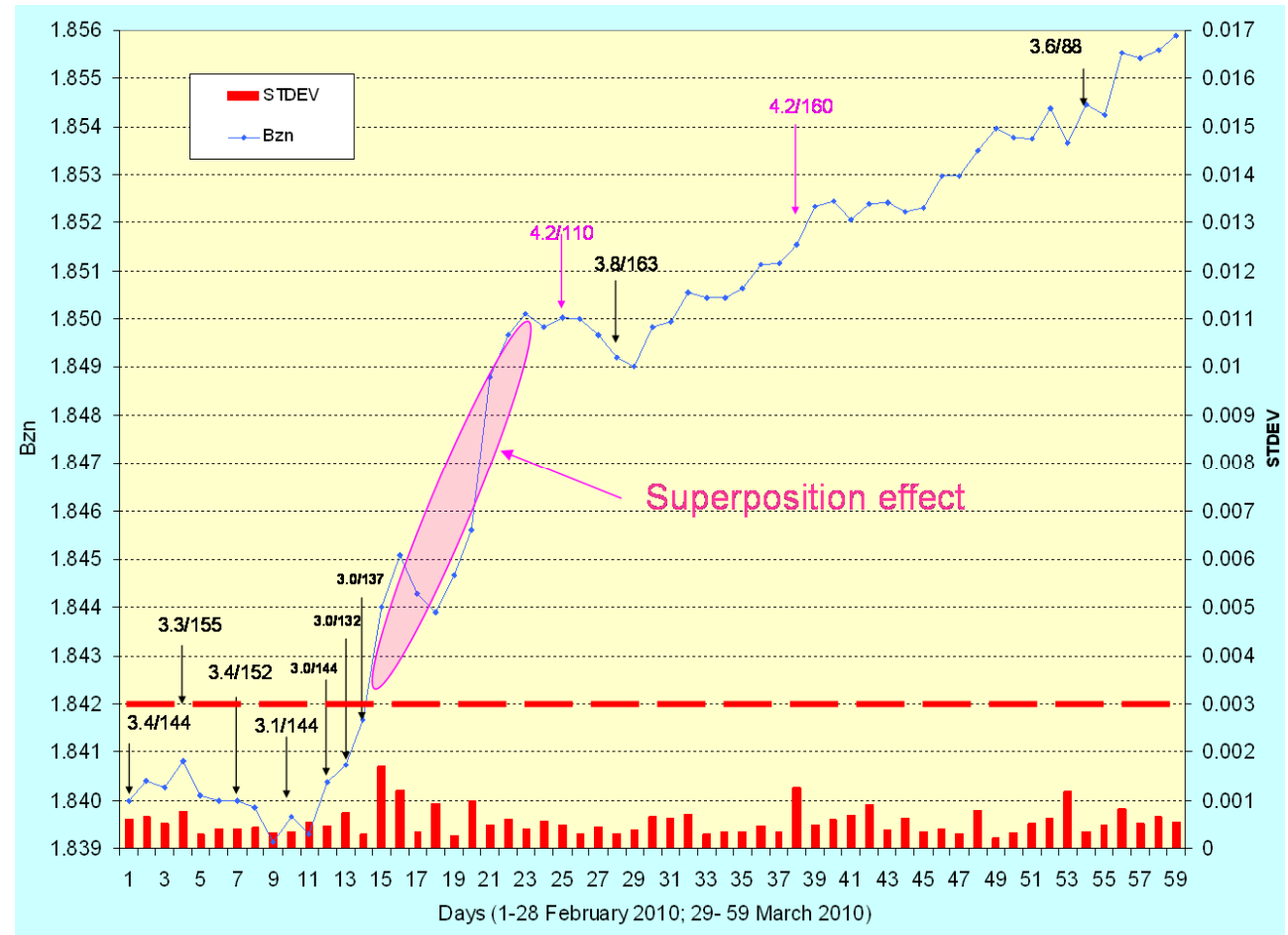

Fig. 10. Bzn and STDEV distributions at the GOPS, within the interval February01- March 31, 2010; vertical arrows are earthquakes and ratio 4.2/110 is the magnitude/hypocenter depth of earthquake in $[\mathrm{km}]$; dashed red line is threshold limit between normal trend and anomalous behaviour of the normalized function Bzn 


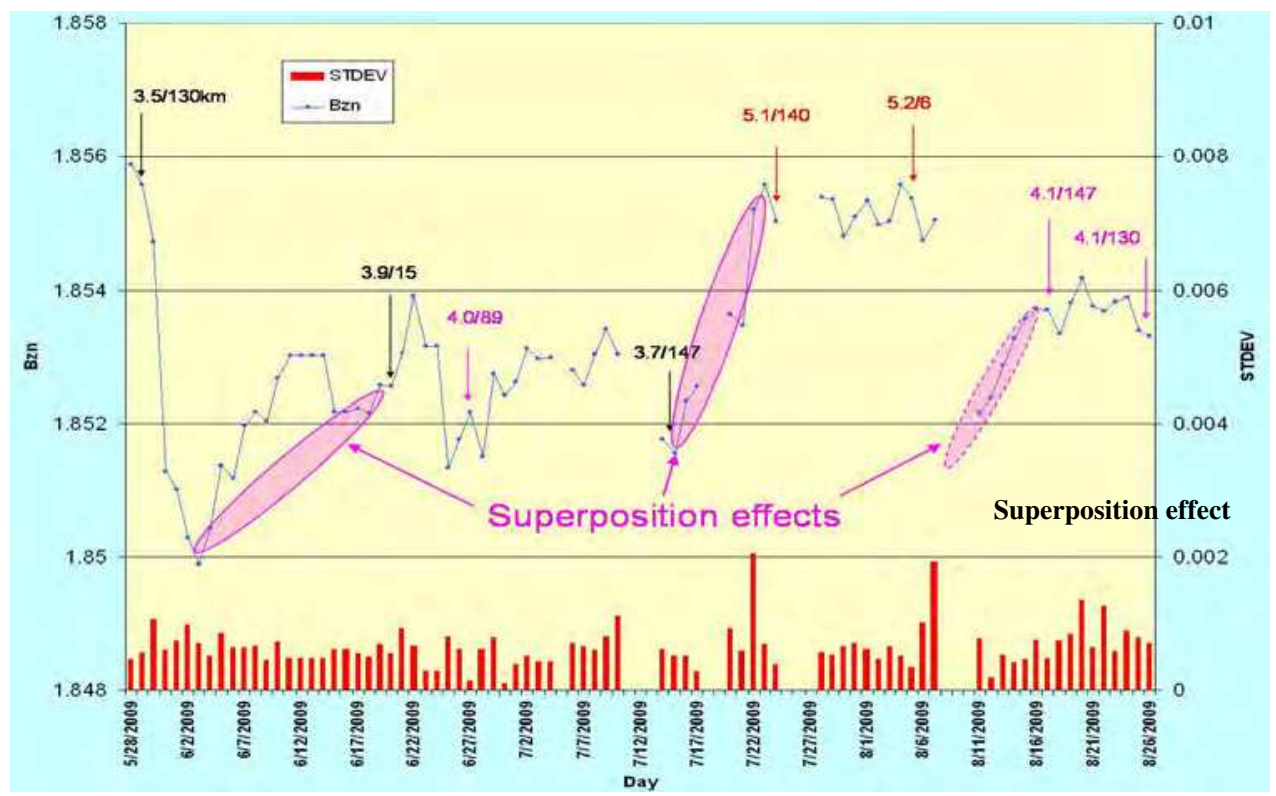

Fig. 11. Bzn and STDEV distributions at the GOPS, within the interval May 28- August 26, 2010; vertical arrows are earthquakes and ratio 5.1/140 is the magnitude/hypocenter depth of earthquake in $[\mathrm{km}]$

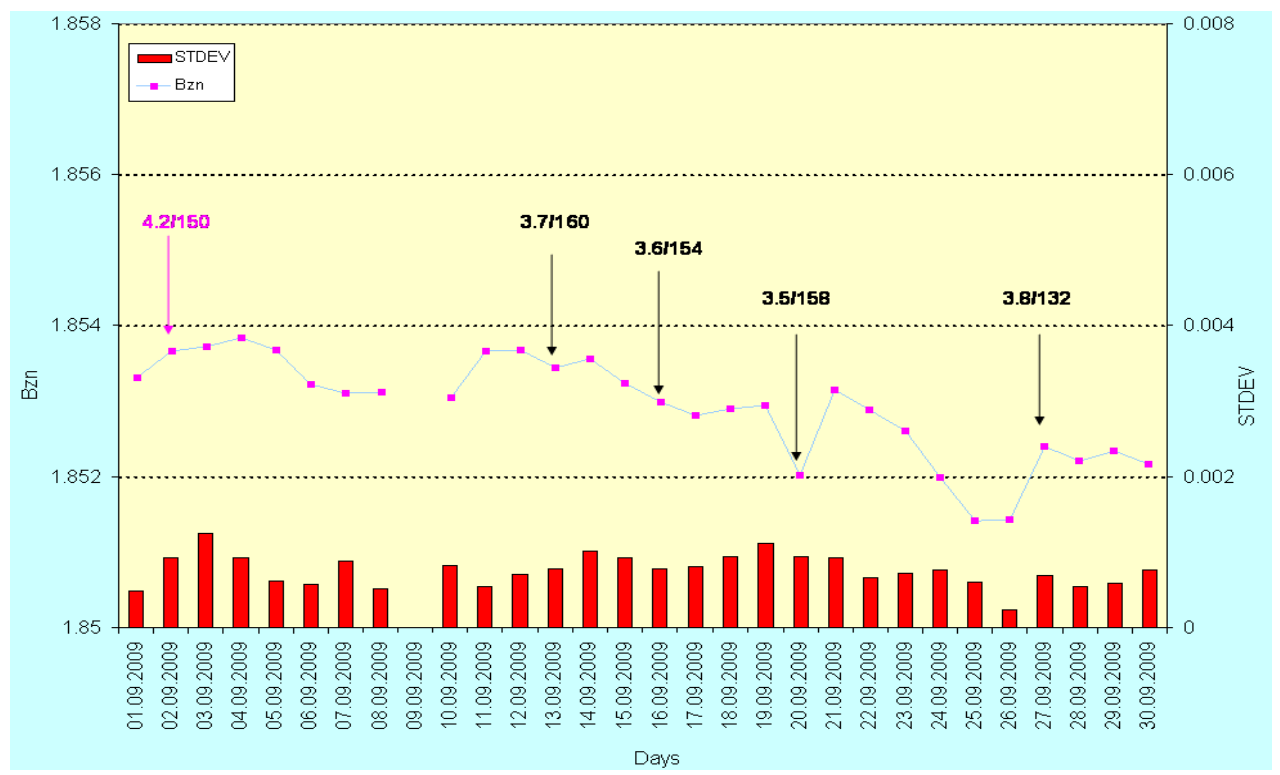

Fig. 12. Bzn and STDEV distributions at the GOPS, within the interval 01February - March 31, 2010; vertical arrows are earthquakes and ratio $4.2 / 150$ is the magnitude/hypocenter depth of earthquake in $[\mathrm{km}]$ 
The local variation of earthquakes energy (Es) carried out for the analyzed interval in 2009 year is shown on Fig. 12. The relationship between earthquake magnitude and energy in foci is:

$$
\log \mathrm{Es}=11.8+1.5 \mathrm{M}
$$

Where: Es is energy [Erg], $\mathrm{M}$ is earthquake magnitude.

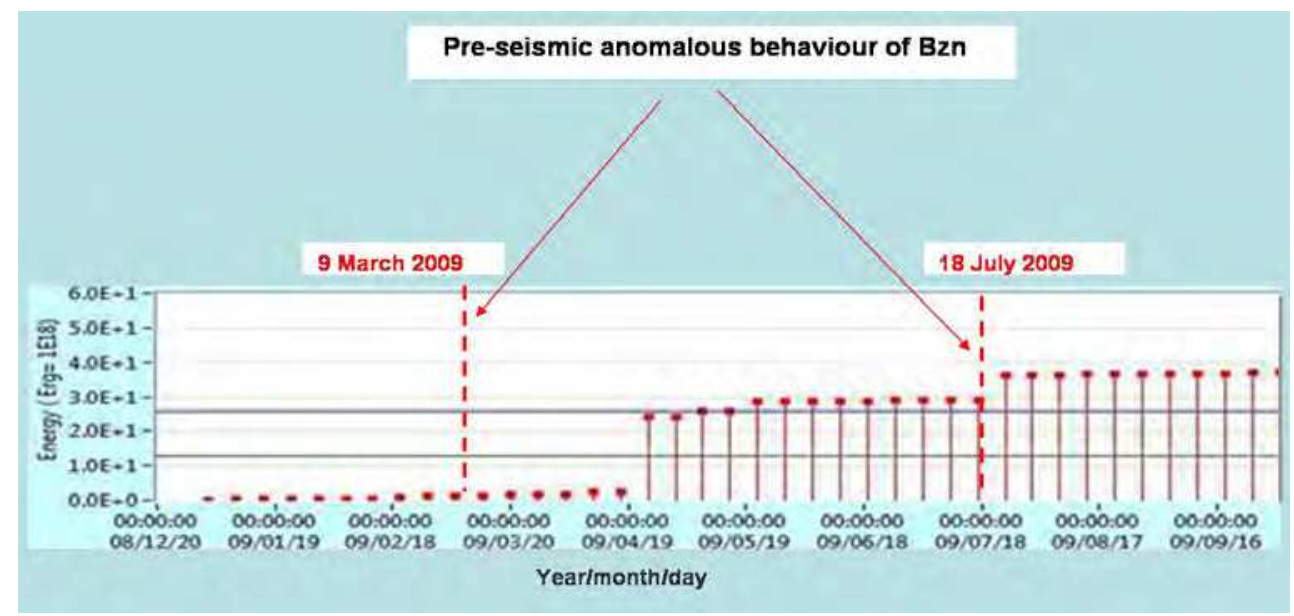

Fig. 13. Variation of earthquakes energy (in foci) on the interval January 01- September 30, 2009: vertical red dashed lines represent lead time of the pre-seismic anomalous behaviour of the normalized function Bzn

It is quite obvious that the pre-seismic anomalous behaviour of Bzn observed on March 9 (Fig.9) and July 18 (Fig.10) respectively, may be correlated with the increased seismic energy reflected by Fig. 13, as follows: more than 15 days interval for the earthquake of M4.0 (March 21) and, about 7 days for earthquakes of M5.1 (July 24). This seismic activity support a possible generation mechanism of the electromagnetic precursors based on the stress generation followed by dehydration of rocks and fluid migration through the faulting system, which may produce concentration of induced currents in highly conductive elongated structure such as Carpathian electrical conductivity anomaly. These induced currents may cause distortion of the vertical geomagnetic component (Fig. 8) which is reflected by increased values of Bzn (Fig.9). The pre-seismic lead time of the normalized function Bzn is between 7days and 15 days for all the data presented in this paper.

\section{Conclusions}

The results carried out in this paper are based on the hypothesis according to the preseismic conductivity changes, due to the fluid migration through faulting system, may generate increased values of the normalized function Bzn proportionally with the intensity of anomalous current concentrations through CECA. 
The normalized function Bzn carried out at GOPS has been analyzed in order to detect its pre-seismic anomalous behaviour related to the intermediate depth earthquakes with $\mathrm{M} \geq 4$. Before all the earthquakes of $M \geq 4$ the Bzn distribution exhibit significant enhancements from the normal trend and the pre-seismic lead time is about 7-15 days. The Bzn average value of 1.842 (Fig.9), associated with earthquakes of $M \leq 3.3$ occurred on the period January 16 - March 7, represents the threshold limit between the normal trend and its pre-seismic anomalous behaviour, taken as possible earthquake precursor.

When anomalous behavior and normal trend domains are much closed, as a multitude of earthquakes of different magnitude occurred at short time intervals, then a superposition effect has been observed.

For the Vrancea zones, two correlations between the magnitude of seismic events and Bzn are highlighted (Fig.14):

i. earthquake of $M \geq 4$ is expected to occur when $B z n \geq 1.847$;

ii. anomalous behaviour of Bzn $\geq 1.854$ may be use as pre-seismic value for an earthquake of $M \geq 5$.

Sometimes, superposition effects may generate exceptions to the above rules.

As this methodology allows us to know always the structure changes after any seismic event (on the base of dimensionality parameters), what permit to use further on the most adequate electromagnetic techniques, it becomes an interesting subject of studying the earthquake mechanism and the associated electromagnetic precursors.

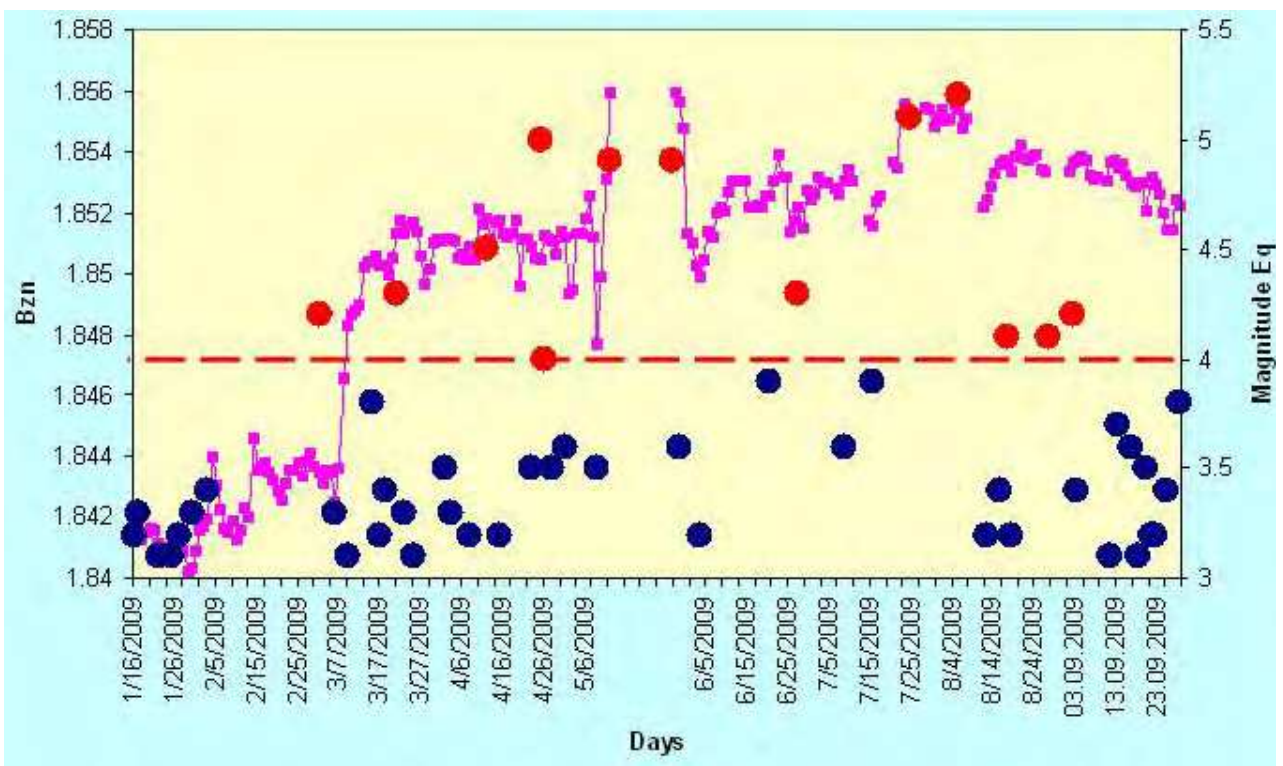

Fig. 14. Distributions of the normalized function Bzn and earthquake magnitude on the 2009 analyzed interval; blue circles are earthquakes with $\mathrm{M}<4$; red circles are earthquakes with $M \geq 4$; red dashed line represents the limit above to which one earthquake of $M \geq 4$ is possible to occur. 


\section{Acknowledgment}

This work was supported by the CNCSIS - UEFISCDI, project number 1028/2009, PN II IDEI code 14/2008. We would also like to thank to the Institute of Geodynamics of the Romanian Academy for providing electromagnetic data and facilities for the present research project.

\section{References}

Bahr, K. (1988). Interpretation of the magnetotelluric impedance tensor: regional induction and local telluric distortion, J. Geophys., 62, pp.119-127

Brace, W.F.; Orange, A. S. \& Madden, T.N. (1965). The effect of pressure on the electrical resistivity of water-saturated crystalline rocks. Journal of Geophysical Res., 70 (22), pp. 5669-5678

Fenoglio, M.A.; Johnston M.J. \& Bierlee, J.D. (1995). Magnetic and electric fields associated with changes in high pore pressure in fault zones: application to the Loma Prieta ULF emissions. J.Geophys.Res. 100, pp. 12951-12958

Fraser-Smith, A.C.; Bernardi, A.; Mc Gill, P.R.; Ladd, M. E.; Halliwell, R.A. \& Villard, Jr. O.G. (1990). Low frequency magnetic field measurements near the epicenter of the M 7.1 Lomma Prieta earthquake. Geophys. Res. Lett., 17, pp.1465-1468.

Freund, F.; Gupta, A.; Butow, S.J. \& Tenn, S. (1999). Molecular hydrogen and dormant charge carriers in minerals and rocs, In: Atmospheric and ionospheric electromagnetic phenomena associated with earthquakes, Hayakawa, \& Molchanov, pp. 839-871, Terra Sci. Publ. Comp., Tokyo

Freund, F. (2000). Time-resolved study of charge generation and propagation in igneous rocks. Journal of Geophysical Res., B, 105, pp.11001-11019

Girbacea, R. \& Frisch, W. (1998). Slab in the wrong place: Lower lithospheric mantle delamination in the last stage of the Eastern Carpathian subduction retreat. Geology 26, pp.611-614

Gotoh, K.; Akinaga, Y.; Hayakawa, M. \& Hattori, K .(2002). Principal component analysis of ULF geomagnetic data for Izu island earthquake in July 2000. J.Atms. Electr. 22, pp.1-12

Gvirtzman, Z. (2002). Partial detachment of a lithospheric root under the southeast Carpathians: toward a better definition of the detachment concept. Geology 30, pp. 51-54

Hattori, K..; Serita, A.; Yoshino, C. Hayakawa, M. \& Isezaki, N. (2006). Singular spectral analysis and principal component analysis for signal discrimination of ULF geomagnetic data associated with 2000 Izu Island earthquake swarm. Phys. Chem. Earth, 31, pp. 281-291

Hayakawa, M. \& Fujinawa, A.Y. (1994). Electromagnetic Phenomena related to Earthquake Prediction, Terra Scientific Pub. Comp, Tokyo

Hayakawa, M. \& Molchanov, O.A. (2002). Seismo-Electromagnetics: Lithosphere-AtmosphereIonosphere Coupling, Terra Scientific Pub. Comp., ISBN 9784887041301, Tokyo

Ismail-Zadeh, A.T.; Panza, G.F. \& Naimark, B.M. (2000). Stress in the descending relic slab beneath the Vrancea region, Romania, Pure Appl. Geophys., 157, pp.111-130 
Johnston M.J.S. (1978). Local magnetic field variations and stress changes near a slip discontinuity on the San Andreas fault. Journal of Geomagnet. And Geoelec., 30, pp. 511-548.

Johnston, M.J.S. (1997). Review of electric and magnetic fields accompanying seismic and volcanic activity. Surv. Geophys., 18, pp. 441-475

Jones, F. W. \& Price, A.T. (1970). The perturbations of alternating geomagnetic fields by conductivity anomaly. Geophys.J.R. Astr. Soc., 20, pp. 317-334

Kaufman, A. A. \& Keller, G.V. (1981). The magnetotelluric sounding method, Elsevier Scientific Publishing Comp., Amsterdam-Oxford-New York.

Khain, V.E. \& Lobkosky, L.I. (1994). Conditions of Existence of the Residual Mantle Seismicity of the Alpine Belt in Eurasia, Geotectonics, 2, pp. 54-60.

Kopytenko, Y.A.; Matiashvili, T.G.; Voronov, P.M. \& Kopytenko, E.A. (1994). Observation of electromagnetic ultralow-frequency lithospheric emission in the Caucasian seismically active zone and their connection with earthquakes, In: Electromagnetic Phenomena related to Earthquake Prediction, Hayakawa \& Fujinawa, 175-180, Terra Scientific Pub. Comp, Tokyo

Linzer, H.-G. (1996), Kinematics of retreating subduction along the Carpathian arc, Romania, Geology 24 (2), pp. 167-170

Liu, J.Y.; Chuo, Y.J.; Shan, S.J.; Tsai, Y.B.; Chen Y.I.; Pulinets, S.A. \& Yu, S.B. (2004). Preearthquake ionospheric anomalies registered by continuous GPS TEC measurements. Annals Geophysicae, 22, pp.1585-1593

Molchanov, O.; Kulchitschy, A. \& Hayakawa, M. (2001). Inductive seismo-electromagnetic effect in relation to seismogenic ULF emission. Natural Hazards and Earth System Sciences, 1, pp. 61-68

Oncescu, M.C. (1984). Deep structure of the Vrancea region, Romania, inferred from simultaneous inversion for hypocenters and 3-D velocity structure. Ann. Geophys., 2, pp. 23-28

Oncescu, M.C.; Burlacu, V.; Anghel, M. \& Smalbergher, V. (1984). Three-dimensional Pwave velocity image under Carpathian Arc. Tectonophysics, 106, pp. 305-319.

Ouzounov, D.; Bryant, N.; Logan, T.; Pulinets, S. \& Taylor, P. (2006). Satellite thermal IR phenomena associated with some of the major earthquakes in 1999-2003. Physics and Chemistry of the Earth, 31, pp.154-163

Parck, S.K.; Johnston, M.J.S.; Madden, T.R.; Morgan, F.D. \& Morrison, H.F. (1993). Electromagnetic precursors to earthquakes in the ULF band: a review of observations and mechanisms. Rev.Geophys., 31, 117-132.

Parkinson, W. (1959). Directions of rapid geomagnetic variations. Geophys. J. R. Astr. Soc. 2, pp.1-14

Parrot, M.; Manninen, J.; Santolik, O.; Nemec, F.; Turner, T.; Rait, T. \& Macusova, E. (2007). Simultaneous observations on board of satellite and on the ground of large-scale magnetospheric line radiation. Geophys. Res. Lett. 34. L19102

Pinna, E.; Soare, A.; Stanica, D. \& Stanica, M. (1993). Carpathian conductivity anomaly and its relation to deep substratum structure. Acta Geodaet. Geophys. et Montanistica, Vol. 27(1), pp.35-45 
Pulinets, S.A.; Gaivaronska, T.A.; Leyva-Contreras, A. \& Ciraolo, L. (2004). Correlation analysis technique reveling ionospheric precursors opf earthquakes. Nat. Hazards Syst. Sci., 4, pp. 697-702

Revol, J.; Day, R. \& Fuller, M. (1977). Magnetic behavior of magnetite and rocks stressed to failure-relation to earthquake prediction. Earth Planet.Sci.Lett., 37, pp.296-306.

Rokityansky, I.I. \& Ingerov, A.I. (1999). Conductive structure of Ukrainian Carpathians from EM observations. Phys. Chem. Earth (A), 24 (9), pp. 849-852

Sperner, B.; Lorenz, F.; Bonjer, K.; Hettel, S.; Muller, B. \& Wenzel, F. (2001). Slab break-offabrupt cut or gradual detachment? New insights from the Vrancea region (SE Carpathians, Romania). Terra Nova, 13, pp.172-179

Sperner, B., the Collaborative Research Centre [CRC], 461 Team (2005). Monitoring of slab detachment in the Carpathians, In:Challenges for Earth Sciences in the 21 ${ }^{\text {st }}$ Century, Wenzel, pp.187-202, Springer-Verlag, Heidelberg

Stanica, D.; Stanica, M.; Piccardi, L.; Tondi, E., \& Cello, G. (2004). Evidence of geodynamic torsion in the Vrancea zone (Eastern Carpahians). Rev. Roum. GEPHYSIQUE, Vol. 48, pp.15-19

Stanica, D., \& Stanica, M. (2007). Electromagnetic monitoring in geodynamic active areas. Acta Geodinamica et Geomaterialia, Vol.4, No.1(145), pp. 99-107

Stanica, D., \& Stanica, D.A. (2010). Constraints on Correlation Between the Anomalous Behaviour of Electromagnetic Normalized Functions (ENF) and the Intermediate Depth Seismic Events Occurred in Vrancea Zone (Romania). Terr. Atmos.Ocean.Sci.,Vol.21, pp.675-683

Stanica, M.; Stanica, D., \& Marin-Furnica, C. (1999). The placement of the Trans-European Suture Zone on the Romanian Territory. Earth Planets Space, 51, 1073-1078

Tramutoli, V.; Cuomo, V; Fillizzola, C., \& Pietrapertosa, C. (2005). Assessing the potential of thermal infrared satellite surveys for monitoring seismically active areas. The case of Kocaely (Izmit) earthquake, August 17-th, 1999. Remote Sensing of Environment, 96, pp.409-426

Trifu, C. I., \& Radulian, M. (1989). Asperity distribution and percolation as fundamentals of earthquakes cycles. Phys. Earth Planet. Inter., 58, pp.277-288

Tronin, A.A.; Biaggi, P.F., \& Molchanov, O.A. (2004). Temperature variations related to earthquakes from simultaneous observations at the ground stations and by satellites in Kamchatka area. Physics and Chemistry of the Earth, Vol. 209, pp. 501-506

Wannamaker, P.E.; Stodt, J.A., \& Rijo, L. (1986). A stable finite element solution for twodimensional magnetotelluric modeling. Geophys. J. R. Astr. Soc., 88, pp. 277-296

Varotsos, P. (2005). The Physics of Seismic Electric Signals (2005), TERRAPUB, ISBN 4-88704136-5,Tokyo

Wiese, H. (1962). Geomagnetische tiefensondierung. Teil II: Die Streichrichtung der Undergrundstrukturen des elektrischen Widerstandes, erschlossen aus geomagnetischen variationen. Geofis. Pura et Appl., 52, pp.83-103

Word, R. D.; Smith, H. W., \& Bostick Jr., F. X. (1970). An investigation of the magnetotelluric tensor impedance method, Electronics Research Center, The University of Texas at Austin, Austin, Texas 78712 
Wortel, M.J.R., \& Spakman, W. (2000). Subduction and slab detachment in MediterraneanCarpathian region. Science, 290, pp. 1910-1917 


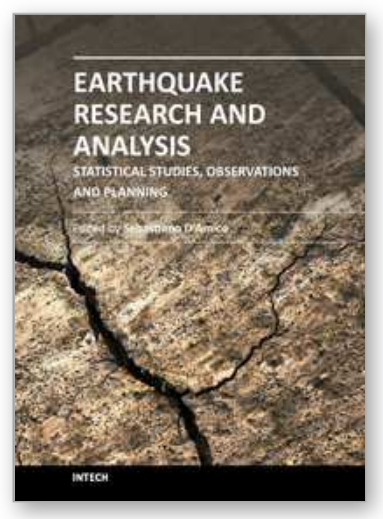

\author{
Earthquake Research and Analysis - Statistical Studies, \\ Observations and Planning \\ Edited by Dr Sebastiano D'Amico
}

ISBN 978-953-51-0134-5

Hard cover, 460 pages

Publisher InTech

Published online 02, March, 2012

Published in print edition March, 2012

The study of earthquakes plays a key role in order to minimize human and material losses when they inevitably occur. Chapters in this book will be devoted to various aspects of earthquake research and analysis. The different sections present in the book span from statistical seismology studies, the latest techniques and advances on earthquake precursors and forecasting, as well as, new methods for early detection, data acquisition and interpretation. The topics are tackled from theoretical advances to practical applications.

\title{
How to reference
}

In order to correctly reference this scholarly work, feel free to copy and paste the following:

Dumitru Stanica and Dragos Armand Stanica (2012). Earthquakes Precursors, Earthquake Research and Analysis - Statistical Studies, Observations and Planning, Dr Sebastiano D'Amico (Ed.), ISBN: 978-953-510134-5, InTech, Available from: http://www.intechopen.com/books/earthquake-research-and-analysisstatistical-studies-observations-and-planning/earthquakes-precursors

\section{INTECH}

open science | open minds

\section{InTech Europe}

University Campus STeP Ri

Slavka Krautzeka 83/A

51000 Rijeka, Croatia

Phone: +385 (51) 770447

Fax: +385 (51) 686166

www.intechopen.com

\section{InTech China}

Unit 405, Office Block, Hotel Equatorial Shanghai

No.65, Yan An Road (West), Shanghai, 200040, China

中国上海市延安西路65号上海国际贵都大饭店办公楼 405 单元

Phone: +86-21-62489820

Fax: $+86-21-62489821$ 
(C) 2012 The Author(s). Licensee IntechOpen. This is an open access article distributed under the terms of the Creative Commons Attribution 3.0 License, which permits unrestricted use, distribution, and reproduction in any medium, provided the original work is properly cited. 